\title{
Free Radical and Antioxidant Levels in Patients with Secondary Peritonitis and Their Prognostic Significance
}

\author{
Yogesh Kumar $^{\mathrm{a}}$ Gurpreet Singh $^{\mathrm{b}}$ Brian R. Davidson ${ }^{\mathrm{a}}$ \\ a University Department of Surgery, Royal Free Hospital, Royal Free and University College Medical School, \\ UCL, London, UK; ${ }^{b}$ Department of Surgery, Post-Graduate Institute of Medical Education and Research (PGIMER), \\ Chandigarh, India
}

\section{Key Words}

Secondary peritonitis $\cdot$ APACHE II $\cdot$ Superoxides .

Antioxidants $\cdot$ Catalase $\cdot$ Superoxide dismutase $\cdot$

Glutathione peroxidase

\begin{abstract}
Background: The clinical outcome of patients with secondary bacterial peritonitis depends on the production of superoxides involved in bacterial killing and the endogenous level of antioxidants. The prognostic significance of their levels has not previously been investigated. Patients and Methods: Forty-five patients undergoing surgery for secondary peritonitis were prospectively evaluated. Severity of illness at admission (APACHE II score) was correlated with admission levels of superoxide radicals and antioxidants (superoxide dismutase (SOD), catalase and glutathione peroxidase). Levels were compared with general surgery controls $(n=10)$. Superoxide and antioxidant levels at admission (day 1) and post-operative days 3 and $5 / 7$ were then correlated with outcome. Results: Nine of the 45 patients died (20\% mortality) and 17 patients had complications (47\% morbidity). The mean APACHE II score on admission was significantly higher among non-survivors than survivors $(p<0.01)$. The APACHE II score on admission correlated with the level of free radicals
\end{abstract}

$(r=0.477, p<0.01)$, catalase $(r=-0.489, p<0.01)$ and SOD $(r=-0.357, p<0.05)$. Admission superoxide levels were higher and antioxidant levels lower in peritonitis patients than controls. Levels did not significantly change following surgical intervention and post-operative levels did not correlate with outcome. Conclusion: The levels of superoxide and antioxidants correlate with the severity of illness on admission in patients with secondary peritonitis, but serial levels following surgical intervention do not predict outcome.

Copyright $\odot 2007$ S. Karger AG, Basel

\section{Introduction}

Generalised peritonitis is associated with a high morbidity and mortality (11-29\%) despite significant advances in diagnosis and treatment by surgery, antibiotic therapy and intensive care support [1-3]. Mortality is particularly high in the elderly and can be accurately determined using the APACHE II score $[1,4,5]$. Mortality usually results from persistent or recurrent intra-abdominal infection, systemic sepsis or multi-system organ failure (MSOF) [6, 7]. Early surgical intervention and antibiotic therapy are essential, but the outcome is largely dependent on the individual's ability to with-

\section{KARGER}

Fax +4161306 1234 E-Mail karger@karger.ch www.karger.com
(C) 2007 S. Karger AG, Basel

0253-4866/07/0245-0331\$23.50/0

Accessible online at:

www.karger.com/dsu
Prof. Brian R. Davidson

Department of Surgery, Royal Free Hospital

Royal Free and University College Medical School

University College London, London NW3 2QG (UK)

Tel. +44 207830 2757, Fax +44 207830 2688, E-Mail b.davidson@medsch.ucl.ac.uk 
stand the inflammatory cascade resulting from systemic sepsis [8].

Oxygen free radicals are generated in large amounts during sepsis and endotoxic shock [9] and are key factors in the development of MSOF [10, 11]. In both experimental models and clinical trials, increased levels of superoxides and decreased antioxidant levels are associated with a poor outcome [12-15]. A recent randomized prospective clinical trial by Nathens et al. [16] and other studies $[17,18]$ have also suggested therapeutic benefit to the use of exogenous antioxidants in septic patients. These studies also observed a difference between the levels of oxidative stress and antioxidants in survivors and non-survivors of sepsis in intensive care unit (ICU) patients. The hypothesis of the present study was that the levels of superoxide and antioxidants may be predictive of outcome in patients undergoing surgery for secondary peritonitis.

\section{Methods}

Patients with peritonitis referred to a tertiary referral surgical service in northern India over a 6-month period were enrolled in a prospective study following fully informed consent. Approval for the study on both healthy volunteers $(n=10)$ and patients with peritonitis $(n=50)$ was gained from the local hospital ethics committee. The healthy volunteers were age- and sex-matched and randomly selected from the surgical outpatient clinic. A detailed history and physical examination was carried out on all patients. Severity of illness was determined at admission using the APACHE II score [5]. The surgical procedure involved definitive surgery for the primary pathology along with peritoneal lavage and drainage. All patients received pre- and post-operative antibiotics (ciprofloxacin and metronidazole). Complications were assessed using a strict protocol for clinical assessment, routine laboratory parameters and imaging. Clinical evaluation included daily recording of temperature, pulse, blood pressure, respiratory rate, oxygen saturation using pulse oximetry, intake-output charting, chest auscultation findings and abdominal girth measurement. Routine laboratory parameters included haematocrit, leukocytes count, CRP, blood urea, serum electrolyte, creatinine and liver function test. Blood gases were done on days 1, 3 and 5/7 following admission. Body fluid cultures were performed on clinical or haematological suspicion of sepsis and antibiotics changed on the basis of the culture results. Imaging included plain chest x-ray on the 3 rd post-operative day and subsequently based on chest auscultation findings. Ultrasound and CT were performed if an intra-abdominal collection was suspected and radiological or surgical drainage performed as indicated.

\section{Blood Sampling for Free Radicals and Antioxidants}

Six millilitres of heparinised venous blood was taken on admission (day 1 ) and on the $3 \mathrm{rd}$ and 7 th day. Blood was centrifuged at 1,800 rpm for 15-20 min and the plasma separated and stored at $-20^{\circ} \mathrm{C}$. For assay, the plasma was defrosted and then centri- fuged for a further $10 \mathrm{~min}$ at $1,800 \mathrm{rpm}$. The supernatant was then decanted. The remaining sediment lining the base of the tube contained neutrophils. Viability of neutrophils was checked by the trypan blue exclusion test [15].

\section{Measurement of Superoxide $\left(\mathrm{O}_{2}^{-*}\right)$}

Since superoxides are unstable in plasma, the isolated neutrophils were subjected to cytochrome $\mathrm{c}$ reduction. Superoxide production was determined at $37^{\circ} \mathrm{C}$ after $4 \mathrm{a}$-phorbol 12 -myristate 13-acetate (Sigma Chemicals, St. Louis, Mo., USA) stimulation on a UV visible spectrophotometer (Shimadzu, Japan) as a superoxide dismutase (SOD) (Sigma Chemicals)-inhibitable reduction of ferricytochrome c (Sigma Chemicals) as described previously [19]. The difference between the amounts of cytochrome c reduced at $550 \mathrm{~nm}$ in the presence and absence of SOD represents the amount of superoxides generated during incubation. Results were expressed as nmol of cytochrome $\mathrm{c}$ reduced $/ 10^{6}$ neutrophils, using the extinction coefficient of cytochrome c as $29.5 \mathrm{~nm} / \mathrm{l} /$ $\mathrm{cm}$.

\section{Measurement of Antioxidants}

Superoxide Dismutase Assay (Sigma Chemicals)

SOD activity was measured in plasma by the method of Kono [20]. This is based on the inhibitory effect of SOD on superoxide anions generated by the photo-oxidation of hydroxylamine chloride and is indicated by reduction of nitroblue tetrazolium dye. The amount of SOD required to inhibit the rate of reduction of nitroblue tetrazolium by $50 \%$ was defined as 1 unit of activity. $\mathrm{SOD}$ activity was expressed as units of $\mathrm{SOD} / \mathrm{mg}$ protein (protein concentration was determined by the method of Lowry et al. [21]).

Catalase Assay (Sigma Chemicals)

The enzyme catalase was assayed in plasma using the method of Luck [22]. This method is based on the decomposition of hydrogen peroxide by catalase which was measured by recording the time (in s) required for a 0.05 decrease in optical density at $240 \mathrm{~nm}$.

Glutathione Peroxidase Assay (Sigma Chemicals)

The activity of glutathione peroxidase (GSH-Px) was estimated in serum according to the method of Paglia and Valentine [23]. The assay is based on the oxidation of glutathione (GSH) to oxidized glutathione (GSSG) catalyzed by GSH-Px. This is coupled with recycling of GSSG back to GSH by glutathione reductase and nicotine adenosine dinucleotide phosphate (NADPH). The decrease in absorbance due to NADPH oxidation is measured at 340 $\mathrm{nm}$. GSH-Px activity was calculated using an extinction coefficient of $6.22^{3} \times 10 \mathrm{M}^{-1} \mathrm{~cm}^{-1}$ for NADPH. The result was expressed as nmol NADPH oxidized $/ \mathrm{min} / \mathrm{mg}$ protein (protein concentration was determined by the method of Lowry et al. [21]).

\section{Statistical Analysis}

The mean $\pm S D$ values for levels of superoxide and antioxidants were compared between survivors and non-survivors, survivors with and without complications and controls using one way ANOVA test. The mean values on day 1 , day 3 and day 5/7 among survivors, non-survivors and controls were compared using paired t test. Correlation between APACHE II, superoxide and antioxidant levels was determined using Spearman's correlation test. 


\section{Results}

Fifty patients with peritonitis were studied prospectively (age 13-85 years, mean $40 \pm 10$ years, 8 were females (16\%)). Five of the 50 patients were considered unfit for surgery following admission and resuscitation. This group of patients on whom the aetiology of the peritonitis was not established succumbed to their illness within 5-7 days and was excluded from further analysis. Forty-five patients underwent exploratory laparotomy, following resuscitation, within $24 \mathrm{~h}$ of admission.

\section{Surgery Findings and Treatment}

Duodenal ulcer perforation was the commonest cause of peritonitis (70\%) and primary closure of the duodenal perforation with an omental patch the commonest operation (67\%). Other aetiologies of secondary peritonitis included perforation of the terminal ileum (6\%), jejunum (6\%), appendix (4\%), stomach (2\%) and sigmoid colon (2\%). Operations for these aetiologies ranged from appendicectomy to bowel resection and anastomosis. Treatment in addition to the surgical procedure included fluid resuscitation, antibiotics guided by culture results, ICU support for ventilation and parenteral nutrition.

\section{Outcome}

Post-operative complications as defined by Copeland et al. [24] were observed in 26 of the 45 patients. These complications were divided into major complications (44.2\%) (requiring ICU or radiological or surgical interventions) and minor complications (56\%) (requiring only pharmacological treatment) (table 1). Respiratory failure was the commonest non-septic complication (12.8\%), while bronchopneumonia was the commonest septic complication (14\%). Of the 45 patients undergoing surgery, 9 died and 36 survived. Of the 36 survivors, 19 had no complications while 17 had complications. None of these patients required either a planned or unscheduled re-laparotomy for treatment of an intra-abdominal collection or anastomotic leak. The causes of death included septicaemia $(n=4)$, bronchopneumonia $(n=6)$, respiratory failure $(\mathrm{n}=7)$, cardiac failure $(\mathrm{n}=3)$ and renal failure $(\mathrm{n}=3)$. The overall mortality was $28 \%$ ( $20 \%$ of those undergoing surgery) and morbidity was $47 \%$.

\section{APACHE II Score and Outcome}

APACHE II scores at admission in the 45 patients who underwent surgery ranged from 0 to 29 against a possible range of 0 to 71 (mean $11 \pm 7$ ). The mean score at admis-
Table 1. Post-operative complications in patients with secondary peritonitis

\begin{tabular}{|c|c|c|}
\hline & \multicolumn{2}{|c|}{ Episodes } \\
\hline & $\mathrm{n}$ & $\%$ \\
\hline \multicolumn{3}{|l|}{ Major complications $^{1}(\mathrm{n}=29)$} \\
\hline Intra-abdominal collection/anastomotic leak & 3 & 10 \\
\hline Respiratory failure & 11 & 38 \\
\hline Cardiac failure & 7 & 24 \\
\hline Renal failure & 8 & 27 \\
\hline \multicolumn{3}{|l|}{ Minor complications ${ }^{2}(n=57)$} \\
\hline Superficial wound infection & 25 & 44 \\
\hline Bronchopneumonia & 12 & 21 \\
\hline Septicaemia & 6 & 10 \\
\hline Hypotension & 9 & 16 \\
\hline Miscellaneous (haemorrhage, DVT, PUO, UTI) & 5 & 9 \\
\hline
\end{tabular}

Total number of patients $=45$; patients with major complications $=26(57 \%)$; patients with minor complications $=14(31 \%)$. $\mathrm{DVT}=$ Deep vein thrombosis; $\mathrm{PUO}=$ pyrexia of unknown origin; $\mathrm{UTI}=$ urinary tract infection.

${ }^{1}$ Major complications (grade III \& IV) [42] defined as those requiring radiological or surgical or ICU intervention despite drug treatment.

${ }^{2}$ Minor complications (grade I \& II) [42] defined as those requiring drug or intravenous therapy or minimal surgical intervention, e.g. removing surgical clip/stitch for wound infection.

Note: Some patients had multiple as well as both major and minor complications, hence more complications than patients.

sion among non-survivors $(19 \pm 7)$ was significantly higher compared to the survivors $10 \pm 6(\mathrm{p}<0.01)$. APACHE II on admission was not significantly different between patients who subsequently developed ( $\mathrm{n}=17$, $9 \pm 2)$ or did not develop $(n=19,8 \pm 1)$ complications. For an APACHE II score of $\leq 10,11-20$ or $>20$, the mortality rate was 8,15 and $71 \%$, respectively.

\section{Superoxide Radicals}

Superoxide levels were significantly higher $(\mathrm{p}<0.01)$ in patients with peritonitis than in controls $(n=10)$. At admission, overall mean superoxide value was $3.91 \pm$ 1.5. The mean value among non-survivors $(4.66 \pm 1.4)$ was not significantly different from survivors (4.42 \pm $0.9)$. Both were significantly higher than controls (1.4 \pm $0.5)(\mathrm{p}<0.01)$ (fig. 1a). The mean value in those developing complications $(4.57 \pm 0.90)$ was not significantly different to those who did not develop complications $(4.29 \pm 0.96)$ but both were significantly higher than controls $(\mathrm{p}<0.01)$. Superoxide levels fell significantly following surgery (day 1 vs. 5/7, p < 0.05) (fig. 1b). 

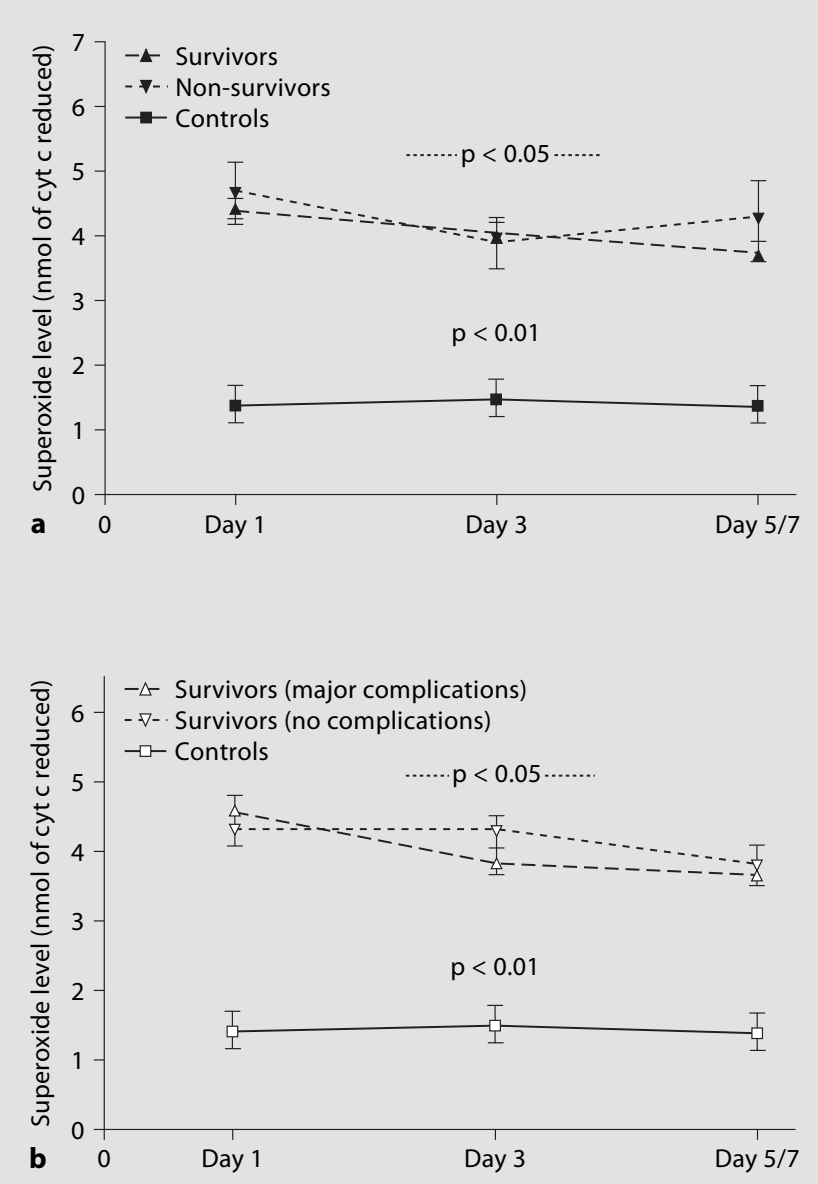

Fig. 1. Superoxide levels in patients with peritonitis compared to controls: (a) survivors and non-survivors, and (b) survivors with major complications and without complications.

\section{Antioxidants}

Catalase. On admission, catalase levels were lower in the patients with peritonitis (survivors and non-survivors) than controls $(\mathrm{p}<0.01)$. Catalase levels were similar between survivors and non-survivors on admission and following surgical intervention (fig. 2a). The mean value of catalase was not significantly different between survivors developing $(1.98 \pm 1.5)$ or not developing complications $(2.09 \pm 2.7)$. Both were significantly lower than controls $(\mathrm{p}<0.01)$ (fig. 2b).

$G S H-P x$. No significant differences in GSH-Px values were found between the groups (fig. 3a, b).

$S O D$. SOD levels on admission in patients with peritonitis $(0.24 \pm 0.16)$ were lower than controls $(0.49 \pm 0.06)$ $(\mathrm{p}<0.01)$ (fig. 4a). No significant differences were found
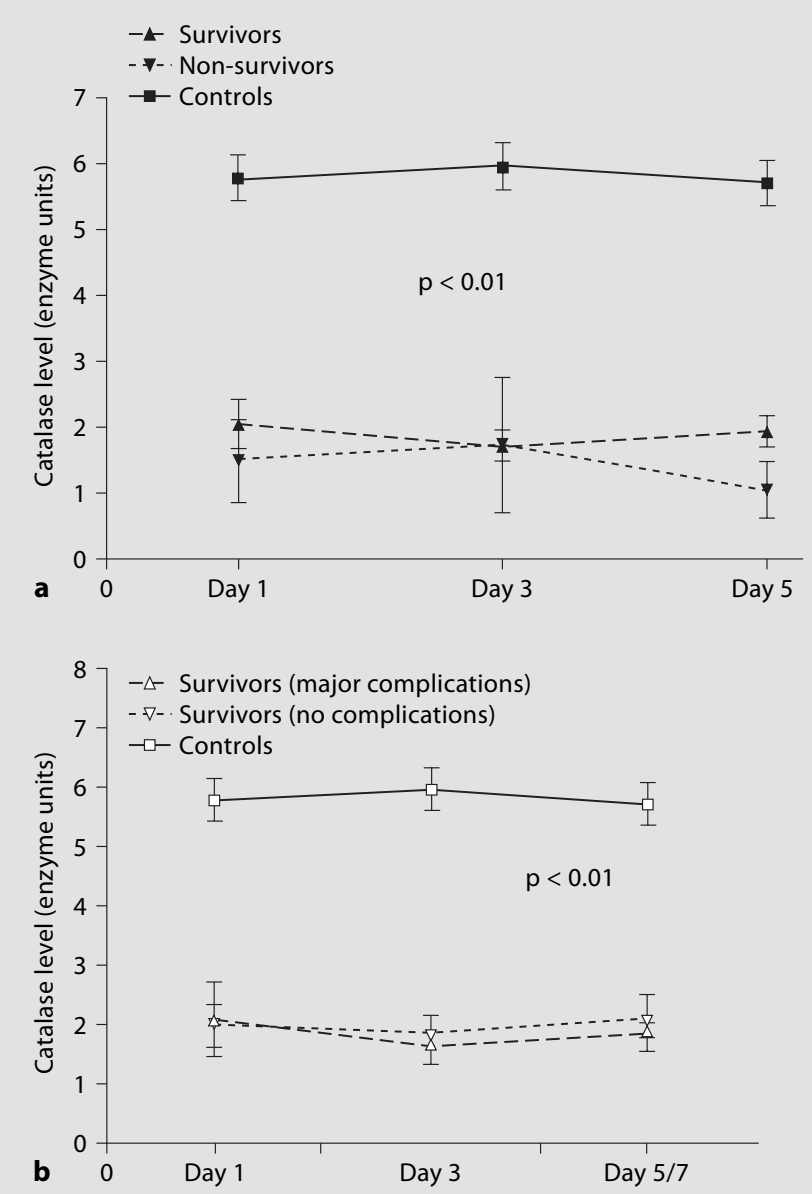

Fig. 2. Catalase levels in patients with peritonitis compared to controls: (a) survivors and non-survivors, and (b) survivors with major complications and without complications.

between survivors and non-survivors and patients with or without complications (fig. 4b).

APACHE II, Superoxides and Antioxidants. A significant correlation was found between the APACHE II score and levels of superoxide radicals $(\mathrm{r}=0.477, \mathrm{p}<0.01)$, catalase $(\mathrm{r}=-0.489, \mathrm{p}<0.01)$ and SOD $(\mathrm{r}=-0.357, \mathrm{p}<$ $0.05)$.

\section{Discussion}

Peritonitis is a common surgical emergency with a high morbidity and mortality even within specialist centres $[2,3]$. Duodenal ulcer perforation was the commonest cause in this study and is the commonest cause of 


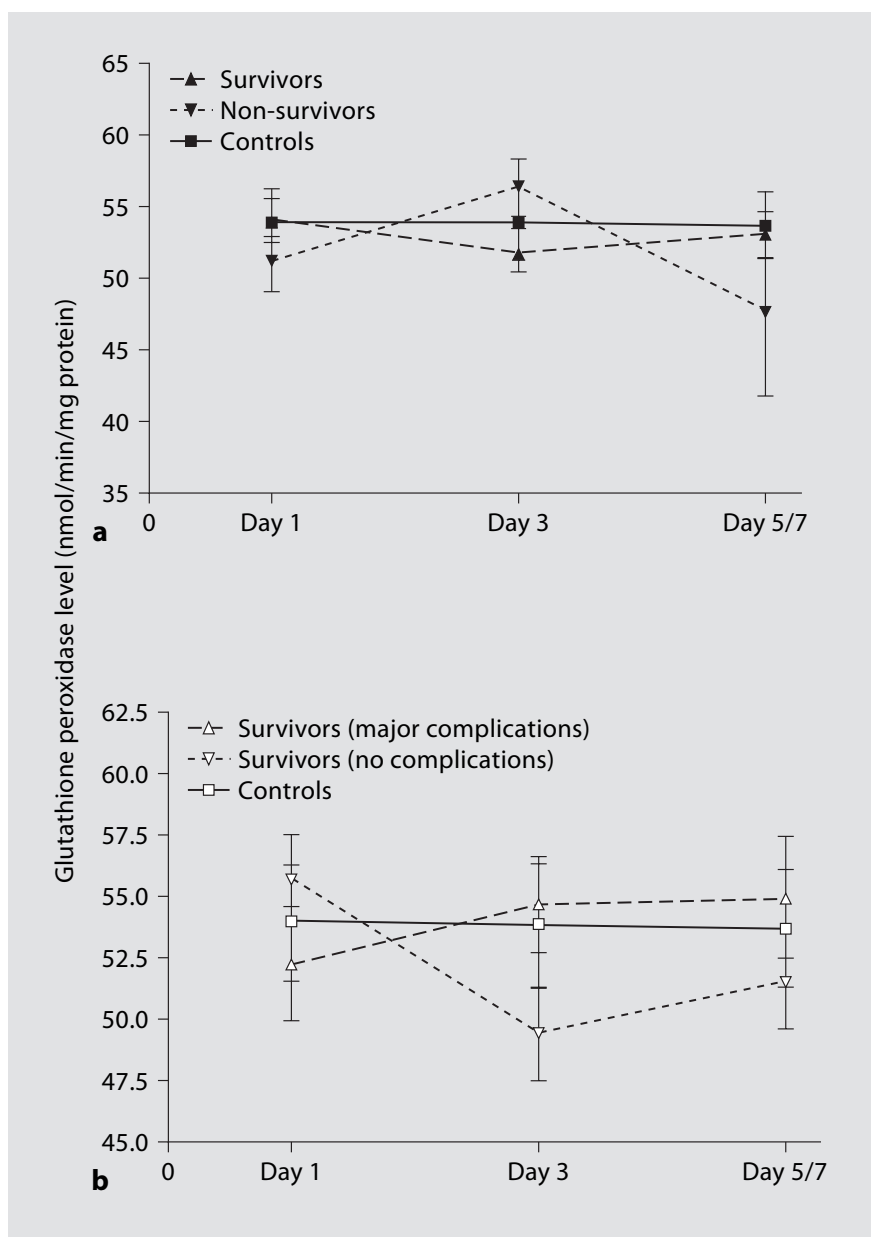

Fig. 3. GSH-Px levels in patients with peritonitis compared to controls: (a) survivors and non-survivors, and (b) survivors with major complications and without complications.

secondary peritonitis in India $[25,26]$. The morbidity and mortality associated with duodenal ulcer perforation is decreasing in developed countries due to widespread use of proton pump inhibitors and Helicobacter eradication therapy [27]. However, the incidence remains high in India and other developing countries where costs may limit such therapy [26]. The mortality of $20 \%$ in this series is similar to other series from India (6-26\%) [26] and some reports from Europe (11-29\%) [1, 28]. The main cause of morbidity and mortality among patients with peritonitis is MSOF and septic shock. Early laparotomy and planned re-laparotomy for septic complications can improve survival [1-3].

The APACHE II score is a validated prognostic indicator in acutely ill patients in the ICU [5]. In this study,

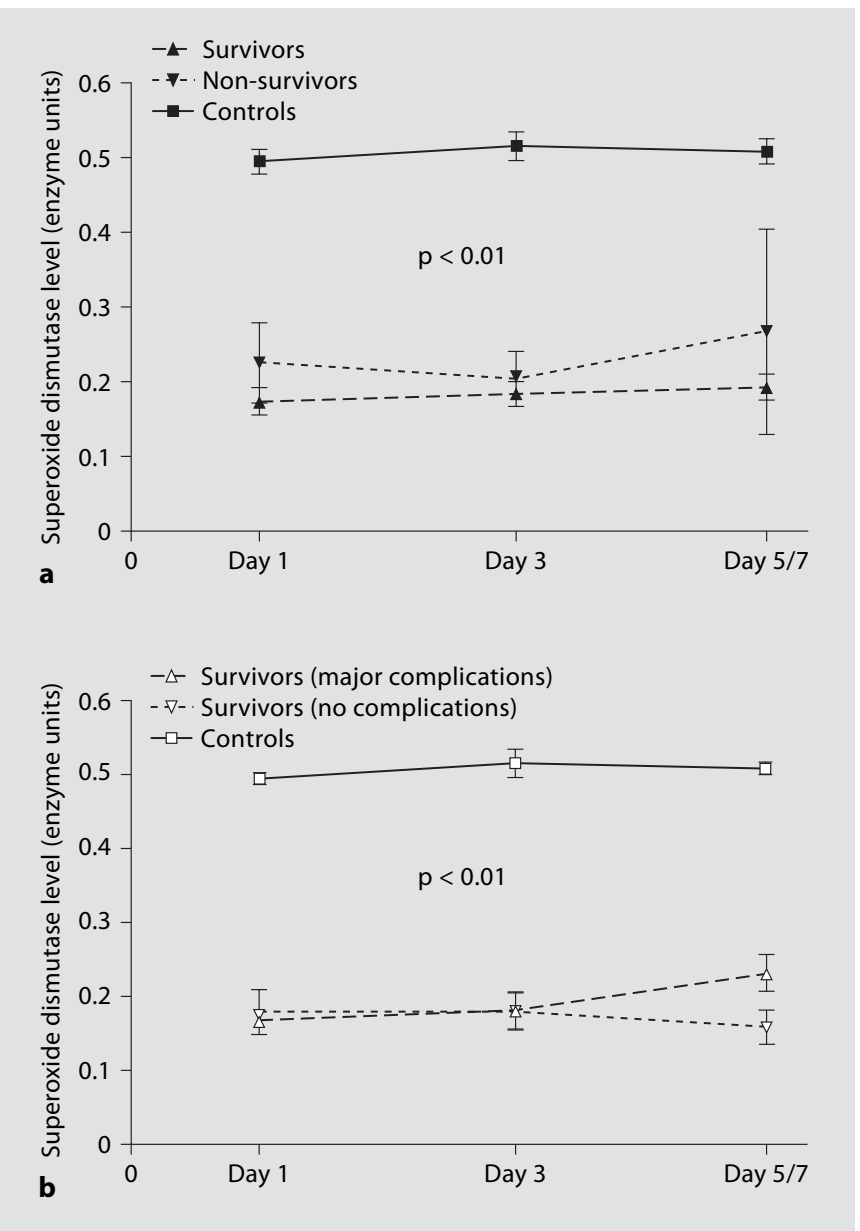

Fig. 4. SOD levels in patients with peritonitis compared to controls: (a) survivors and non-survivors, and (b) survivors with major complications and without complications.

APACHE II correlated well with mortality, a finding previously reported in patients with acute peritonitis [29]. The mortality observed in patients with a low APACHE II score $(\leq 10)$ was due to cardiac events. Events in the low-risk category are unexpected and an underlying cause should be anticipated $[29,30]$. The correlation between APACHE II score and superoxide radicals and antioxidants (catalase and SOD) has not previously been reported in intra-abdominal sepsis and would suggest an oxidant and antioxidant imbalance related to the severity of illness [31, 32].

In keeping with the findings of the present study, patients with peritonitis have previously been shown to have increased levels of oxidative stress compared with healthy controls [11]. Following surgery, superoxide lev- 
els decreased but levels did not correlate with the subsequent outcome. This may relate to the development of secondary complications such as respiratory or renal failure as part of the systemic inflammatory response syndrome. Surgical trauma could be another factor responsible for elevated superoxides. Laparotomy and bowel handling alters neutrophil function with production of proinflammatory mediators including TNF- $\alpha$ and reactive oxygen species [33].

Levels of the antioxidants SOD and catalase were found to be significantly reduced in patients with peritonitis in keeping with previous reports [34]. However, GSH-Px levels did not differ from healthy controls in the present study but were reduced in previous studies on septic patients $[18,35,36]$. This difference may be related to the adequacy of replenishing micronutrients such as selenium in parentral nutrition. In patients with severe infection there is an early and marked decrease in plasma selenium due to increased metabolic use and the concentration of GSH-Px is dependent on selenium levels $[18,37$, 38].

The present study contrasts with the findings of Cowley et al. [34] who found antioxidant levels to be higher in survivors than non-survivors of severe sepsis at 5-7 days following ICU admission. This may reflect differences in the patient cohort as none of the patients in the study by Cowley et al. had surgical intervention for sepsis. Antioxidant levels return to baseline within $12 \mathrm{~h}$ of elective surgery [34], but with emergency surgery for peritonitis a persistent post-operative inflammatory response would be anticipated. Patients with complications following surgery for peritonitis may have been anticipated to have reduced antioxidant levels as with the non-survivors in the study by Cowley et al. No such differences were noted possibly related to the wide range of post-operative levels. The assay used by Cowley et al. measured the plasma total antioxidant capacity, whereas the current study measured the level of different antioxidant enzymes. Total antioxidant capacity is an attractive option as a single test but it measures predominantly the low-molecular-weight chain-breaking antioxidants which may not reflect the levels of individual antioxidant enzymes [39].

The nutritional status of a patient before and following surgery could influence the antioxidant status. Patients presenting with secondary peritonitis usually have a poor nutritional status [40]. A lack of protein leads to deficiency of zinc which is a cofactor for SOD formation [41].

\section{Conclusion}

This study has confirmed that in patients with generalized peritonitis the APACHE II score is helpful in predicting outcome. Oxidative stress is elevated, while the antioxidants catalase and SOD are reduced in intra-abdominal sepsis. Levels are not affected by laparotomy for secondary peritonitis and do not correlate with outcome.

\section{Acknowledgements}

I am thankful to thesis grant committee of PGIMER for grant support and Dr. Alka Mehta of the Department of Experimental Medicine, PGI, Chandigarh, for her precious help in processing the study samples in the laboratory and the Department of Statistics, PGI, Chandigarh, and Mr. Richard Morris, Hospital Statistician, Royal Free Hospital, London, for the help with the analysis and presentation of the results.

\section{References}

1 Mulier S, Penninckx F, Verwaest C, Filez L, Aerts R, Fieuws S, Lauwers P: Factors affecting mortality in generalized postoperative peritonitis: multivariate analysis in $96 \mathrm{pa}-$ tients. World J Surg 2003;27:379-384.

-2 Bosscha K, van Vroonhoven TJ, van der Werken C: Surgical management of severe secondary peritonitis. Br J Surg 1999;86: 1371-1377.

3 Wittmann DH, Schein M, Condon RE: Management of secondary peritonitis. Ann Surg 1996;224:10-18.

\footnotetext{
$\checkmark$

4 Poenaru D, Christou NV: Clinical outcome of seriously ill surgical patients with intraabdominal infection depends on both physiologic (APACHE II score) and immunologic (DTH score) alterations. Ann Surg 1991;213: 130-136.

5 Knaus WA, Draper EA, Wagner DP, Zimmerman JE: APACHE II: a severity of disease classification system. Crit Care Med 1985; 13:818-829.

6 Hau T: Bacteria, toxins, and the peritoneum. World J Surg 1990;14:167-175.

7 Marshall JC: Intra-abdominal infections. Microbes Infect 2004;6:1015-1025.
}

8 Schein M: Surgical management of intra-abdominal infection: is there any evidence? Langenbecks Arch Surg 2002;387:1-7.

$\checkmark 9$ Closa D, Folch-Puy E: Oxygen free radicals and the systemic inflammatory response. IUBMB Life 2004;56:185-191.

10 Demling R, LaLonde C, Ikegami K, Picard L, Nayak U: Alpha-tocopherol attenuates lung edema and lipid peroxidation caused by acute zymosan-induced peritonitis. Surgery 1995;117:226-231. 
11 Galley HF, Davies MJ, Webster NR: Xanthine oxidase activity and free radical generation in patients with sepsis syndrome. Crit Care Med 1996;24:1649-1653.

$\checkmark 12$ Goode HF, Cowley HC, Walker BE, Howdle PD, Webster NR: Decreased antioxidant status and increased lipid peroxidation in patients with septic shock and secondary organ dysfunction. Crit Care Med 1995;23:646651.

$>13$ Ritter C, Andrades M, Frota Junior ML, Bonatto F, Pinho RA, Polydoro M, Klamt F, Pinheiro CT, Menna-Barreto SS, Moreira JC, Dal Pizzol F: Oxidative parameters and mortality in sepsis induced by cecal ligation and perforation. Intensive Care Med 2003;29: 1782-1789.

14 Takeda K, Shimada Y, Amano M, Sakai T, Okada T, Yoshiya I: Plasma lipid peroxides and $\alpha$-tocopherol in critically ill patients. Crit Care Med 1984;12:957-959.

- 15 Powell RJ, Machiedo GW, Rush BF Jr, Dikdan GS: Effect of oxygen-free radical scavengers on survival in sepsis. Am Surg 1991;57: 86-88.

16 Nathens AB, Neff MJ, Jurkovich GJ, Klotz P, Farver K, Ruzinski JT, Radella F, Garcia I, Maier RV: Randomized, prospective trial of antioxidant supplementation in critically ill surgical patients. Ann Surg 2002;236:814822 .

-17 Fujimura N, Sumita S, Aimono M, Masuda Y, Shichinohe Y, Narimatsu E, Namiki A: Effect of free radical scavengers on diaphragmatic contractility in septic peritonitis. Am J Respir Crit Care Med 2000;162:2159-2165.

-18 Ogilvie AC, Groeneveld AB, Straub JP, Thijs LG: Plasma lipid peroxides and antioxidants in human septic shock. Intensive Care Med 1991;17:40-44.

-19 Wanten GJ, Naber AH, Kruimel JW, Tool AT, Roos D, Jansen JB: Influence of structurally different lipid emulsions on human neutrophil oxygen radical production. Eur J Clin Invest 1999;29:357-363.
20 Kono Y: Generation of superoxide radical during autoxidation of hydroxylamine and an assay for superoxide dismutase. Arch Biochem Biophys 1978;186:189-195.

21 Lowry OH, Rosebrough NJ, Farr AL, Randall RJ: Protein measurement with the Folin phenol reagent. J Biol Chem 1951;193:265275.

22 Luck H: Catalase; in Bergmeyer HO (ed): Methods of Enzymatic Analysis. New York, Academic Press, 1971, pp 885-893.

23 Paglia DE, Valentine WN: Studies on the quantitative and qualitative characterization of erythrocyte glutathione peroxidase. J Lab Clin Med 1967;70:158-169.

24 Copeland GP, Jones D, Walters M: POSSUM: a scoring system for surgical audit. Br J Surg 1991;78:355-360.

25 Dorairajan LN, Gupta S, Deo SV, Chumber S, Sharma L: Peritonitis in India - a decade's experience. Trop Gastroenterol 1995;16:3338.

26 Gupta S, Kaushik R: Peritonitis - the Eastern experience. World J Emerg Surg 2006;1:13.

27 Higham J, Kang JY, Majeed A: Recent trends in admissions and mortality due to peptic ulcer in England: increasing frequency of haemorrhage among older subjects. Gut 2002;50:460-464

28 Irvin TT: Mortality and perforated peptic ul cer: a case for risk stratification in elderly patients. Br J Surg 1989;76:215-218.

29 Schein M, Gecelter G, Freinkel Z, Gerding H: APACHE II in emergency operations for perforated ulcers. Am J Surg 1990;159:309313.

30 Schein M: Acute surgical disease and scoring systems in daily surgical practice. Br J Surg 1988;75:731-732.

31 Crimi E, Sica V, Williams-Ignarro S, Zhang $\mathrm{H}$, Slutsky AS, Ignarro LJ, Napoli C: The role of oxidative stress in adult critical care. Free Radic Biol Med 2006;40:398-406.

32 Roth E, Manhart N, Wessner B: Assessing the antioxidative status in critically ill patients. Curr Opin Clin Nutr Metab Care 2004;7:161-168.
33 Shijo H, Iwabuchi K, Hosoda S, Watanabe H, Nagaoka I, Sakakibara N: Evaluation of neutrophil functions after experimental abdominal surgical trauma. Inflamm Res 1998;47: 67-74.

34 Cowley HC, Bacon PJ, Goode HF, Webster NR, Jones JG, Menon DK: Plasma antioxidant potential in severe sepsis: a comparison of survivors and nonsurvivors. Crit Care Med 1996;24:1179-1183.

>35 Fujimura N, Sumita S, Aimono M, Masuda Y, Shichinohe Y, Narimatsu E, Namiki A: Effect of free radical scavengers on diaphragmatic contractility in septic peritonitis. Am J Respir Crit Care Med 2000;162:2159-2165.

36 Leff JA, Parsons PE, Day CE, Taniguchi N, Jochum M, Fritz H, Moore FA, Moore EE, McCord JM, Repine JE: Serum antioxidants as predictors of adult respiratory distress syndrome in patients with sepsis. Lancet 1993;341:777-780.

-37 Forceville X, Vitoux D, Gauzit R, Combes A, Lahilaire P, Chappuis P: Selenium, systemic immune response syndrome, sepsis, and outcome in critically ill patients. Crit Care Med 1998;26:1536-1544

38 Jefferies H, Coster J, Khalil A, Bot J, McCauley RD, Hall JC: Glutathione. ANZ J Surg 2003;73:517-522.

39 Morris DM, Smith HO, Liu W, Genesen MC, Vander Jagt DH, Glew RH, Fry DE: Are antioxidant levels measured immediately postoperatively an indicator of magnitude of injury? Am J Surg 2000;180:212-216.

40 Kaur N, Gupta MK, Minocha VR: Early enteral feeding by nasoenteric tubes in patients with perforation peritonitis. World J Surg 2005;29:1023-1027.

41 Fang YZ, Yang S, Wu G: Free radicals, antioxidants, and nutrition. Nutrition 2002;18: 872-879.

42 Dindo D, Demartines N, Clavien PA: Classification of surgical complications: a new proposal with evaluation in a cohort of 6,336 patients and results of a survey. Ann Surg 2004;240:205-213. 